\title{
MS35-P06 | NOVEL COORDINATION COMPOUNDS FOR BIOLOGICAL APPLICATIONS
}

Garcia-Granda, Santiago (University Oviedo - CINN, Oviedo, ESP); Abdelbaky, Mohammed S. M. (University Oviedo - CINN, Oviedo (Asturias), ESP); Direm, Amani (Université Abbes Laghrour, Khenchela, DZA); Moeini, Keyvan (Payame Noor University, Tehran, IRN)

The interaction of transition metal ions with biological molecules provides one of the most promising class of coordination chemistry. The biological activity of such class makes them the fascinating candidate for biomedical uses. Imidazole occurs in most proteins as part of the side chain of histidine and constitutes a binding site for various transition metal to form imidazole based complexes that display a variety of pharmacological effects, including antitumor, superoxide dismutase and catecholase activities [1]. On the other hand, Schiff bases ligands and their complexes show interesting biological effects such as anticancer antimicrobial and urease inhibitory activates. Herein, and in order to contribute to the study of these systems, Schiff bases imidazole based complexes with different metal ions are presented. The resulting compounds have been structurally characterized and their biological activates were investigated. They have shown remarkable anticancer, antimicrobial and antifungal inhibition activities, which have been predicted by exploring the computational chemical reactivity of the these complexes [2]

Keywords: Coordination networks; imidazole-based copper complexes; topological analysis; Ab-initio calculations; magnetic properties; biological properties.

Acknowledgements: The financial support from Université Abbes Laghrour Khenchela, Algeria, Spanish MINCIU (MAT2016-78155-C2-1-R,), Principality of Asturias (GRUPIN14-060/GRUPIN-IDI/2018/000170) and FEDER is acknowledged.

[1] G. Tabbi, W.L. Driessen, J. Reedijk, R. P. Bonomo, N. Veldman, A.L. Spek, Inorg Chem, 36(6),1997,1168-1175 [2] A. Direma, M.S.M. Abdelbaky, K. Sayın, A. Cornia, O. Abosede, S. García-Granda, Inorg. Chim. Acta 478, 2018, 59-70 